\title{
Non-Governmental Organisation Emergency Food Relief in Rural Zimbabwe: Implications on Labour Supply and Self Sustenance
}

\author{
Tafadzwa R Chikwanha
}

Department of Economics, University of Fort Hare, Email: chikwanhat@gmail.com

\section{Free Ncube}

Department of Economics, University of Fort Hare, Email:201013417@ufh.ac.za

\section{Doi:10.5901/mjss.2014.v5n23p91}

\begin{abstract}
The study sought to determine whether NGO food relief administered in rural Zimbabwe has had impacts of the citizens' perceptions towards work and self sustenance. Secondarily, the study sought to measure whether the degree of impact of the NGO food (if it exists). Despite the recent attention granted to studies concentrating on the impacts of foreign aid in SubSaharan Africa, very little literature exists on the impacts of food aid in particular even more so the Zimbabwean perspective. The possible labour market and development impacts of such welfare benefits have been extensively studied and published theoretically. It is prudent though, to know at least the ranges of the quantitative estimates of these impacts. The study sought to provide empirical literature on the level of influence of continuous granting of humanitarian food aid by NGOs on rural citizens' perspective towards labour and production. The study implemented a maximum binary Probit model to determine the possible influence on each variable on households approach towards work. The study found that persistent food relief among other variables such as gender of household leader, size of household and education level attained were significant in influencing work ethic among recipients of humanitarian assistance.
\end{abstract}

Keywords: Emergency food aid, labour supply, self sustenance, Zimbabwe.

\section{Introduction}

Zimbabwe, like many other countries in the region and of similar socio-economic standing, is a recipient of foreign and domestically sponsored non-governmental aid. Historically, Zimbabwe was considered the 'bread basket' of the Southern African Development Community ${ }^{1}$ and a net exporter of agricultural commodities. Years of inconsistent rainfalls and changing weather patterns have severely degraded the level of agricultural productivity within the nation. Furthermore, illegal economic sanctions instigated by the United States congress and supported by their European allies through the Zimbabwe Democracy and Economic recovery Act (ZIDERA) of 2001 have exacerbated the situation². The resultant scenario has been a shortage of the much needed maize in the country. The State has resorted to importation of maize from neighbouring countries. Regardless, the excess demand for maize has not been severely dampened from year to year. The shortages and poor harvests have led to poverty and in some cases severe poverty especially in the rural areas. Contrary to the actions of their governments, various non-governmental organizations (NGOs) involved in food aid and relief have invested significantly in the areas were drought has had devastating effect. The United States remains the major source of food aid followed by the European Union, Australia and Canada (Habte and Mielke, 2005).

Contrary to the lay man perspective, food aid borders beyond the simplistic notion of humanitarian dispersal of food hand outs. It involves various complex socio-economic concepts and comprises three main categories i.e. program, project and humanitarian/emergency (Awokuse, 2006). Program food aid involves foreign food aid granted through intergovernment grants, loans and concessions with the purpose of easing the recipient State's fiscal or balance of payments burdens (Barrett and Maxwell, 2005). Project food aid is principally granted with the intention to incentivize targeted

\footnotetext{
1 From here on SADC

2 ZIDERA (S. 494) was passed by US congress with the so called intention to foster transition to "democratic rule" and economic upturn and growth in Zimbabwe.
} 
socio-economic development and improvement agendas for instance education, infrastructure growth and work (Awokuse, 2006). Emergency/humanitarian food aid, which involves the granting of food hand outs to citizens has become of primary concern to developing economies due to its rapid growth rate and ultimately indeterminable consequences. The question beckons whether emergency food aid fosters the development of a dependency syndrome and disillusionment towards subsistence agricultural production.

Droughts and the resultant poverty and food insecurity remain major issues of concern for Zimbabwe. The prevailing poverty rates and drought patterns have had considerable effects on the population (the burden is borne more by the poor, who comprise the larger part of the population) and thus sustainable planning and growth of the economy. The Zimbabwe Vulnerability Assessment Committee (ZimVAC) 3 forecasted that an excess of 1.6 million people would have access to insufficient food in 2013 (UNWFP, 2012). Globally, poverty and food insecurity are conceptualized as a twin social and economic predicaments, more so in sub-Saharan Africa. NGOs have gotten involved in large numbers in attempt to help mitigate these problems. Despite the globally demonstrated role of NGO food relief in mitigating poverty and food insecurity in the short term, policymakers and academics retain a degree of skepticism towards the sustainability of such support and its possible ramifications on national welfare. Even so long after the inception of the NGO food aid programs, the long term impacts, both social and economic are not clearly defined and cannot be easily quantified.

The more radical of sceptics perceive the perennially continuous food aid as a perverse incentive in Zimbabwe. In their view, persistent food aid is a basis upon which the recipients, especially the younger generation, cease to produce for themselves. The result is ever escalating dependency and an incessantly cyclical trend of aid emission. Therefore, NGO food relief may in fact trigger a form of moral hazards 4 . Where moral hazards affect behaviours, negative social implications will escalate (Lipsey and Chrystal, 2007). The dilemma is whether the food aid acts as a variable associated with a decrease in the willingness to work and therefore long term self sustenance of rural citizens in Zimbabwe. Dependency on food aid might therefore be generated where individual, households or societies show they cannot meet their essential needs without aid (Lentz, Barrett and Hoddinott, 2005). Dependency may take two forms i.e. desired and undesired. The desired form of dependency is one that improves social welfare. It is dependency that is legitimate for instance from a household comprising members who are unable to cater for themselves completely like children or the elderly. The undesired dependency forms as a consequence of cost reduction on the part of a recipient who is otherwise able to sustain himself (Harvey and Lind, 2005).

\section{An Overview of Food Aid in Zimbabwe}

Figure 1: Trends in Official Development Assistance in Zimbabwe

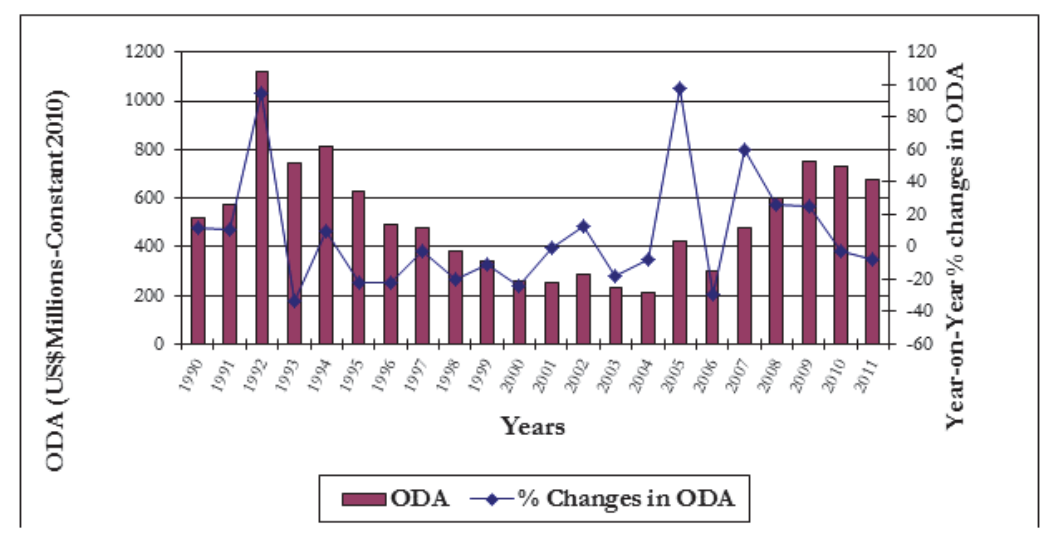

Source: OECD (2013)

\footnotetext{
${ }^{3}$ The Zimbabwe Vulnerability Assessment Committee is responsible for determination of prejudiced and vulnerable social circles in Zimbabwe and suggesting policy measures on improving their status.

${ }^{4}$ Moral hazards are the prospects that a partly or fully insulated individual may behave differently from the way he/she would have behaved had he/she not been covered or had been fully exposed to the risk (Lipsey and Chrystal, 2007: 290). 
Figure 1 illustrates the variations in Official Development Assistance (ODA) in Zimbabwe. Although humanitarian aid comprises a portion of ODA, according to the Global Humanitarian Assistance Development Initiative (2011), in Zimbabwe it has been constantly around 40\% of ODA and even more so in drought years. The peak of humanitarian aid was received during the infamous 1992 drought season. It contributed to an over 90\% growth in ODA, which was almost double the previous year. From this period onward, there was a general decline in ODA and humanitarian assistance. The 2002 drought triggered a nearly 20\% rise in ODA, (although significantly less compared to the beginning of the previous decade), from the previous year. In 2005, a 100\% rise from 2004 was experienced. This was likely caused by the massive degradation in incomes and food security instigated by the initial stages of an unprecedented economic meltdown. The rising trend occurred until reaching a 21 $1^{\text {st }}$ century peak in 2009. From then onwards, the levels of ODA have been dropping largely because of the marked improvement in economic performance and living standards. In 2010, humanitarian aid to Zimbabwe consisted $12.5 \%$ of Gross National Income (GNI) (OECD, 2013). In 2011, Zimbabwe was the $18^{\text {th }}$ largest recipient of humanitarian assistance at US\$163 million.

\section{A Brief Summary of Supporting Literature}

This study is underpinned by two major labour market theories. The primary theory is the Theory of Labour supply. The focal points of the model are its analyses of the impacts of wage-related income and non-wage income on labour supply and the general approach towards work. The model proposed the backward bending labour supply curve. The model suggested that individuals are incentivised to work by wage income until it reaches a point of inflection were the wage increases foster a propensity towards leisure. The supporting hypothesis is the Theory of labour force participation which argues that individuals are faced with either of two labour market decisions: whether to work or not. It also postulates work related income as the major determinant of participation in the labour force. The model incorporates various socioeconomic variables as determinants of the decision to work.

This study is bound on the bases of other studies conducted in low income countries that are notable recipients of humanitarian food aid. Related empirical literature exists in the form of Hoddinnott (2003), Habte and Mielke (2005), Hammond, Bush, Savage and Harvey (2005), Barrett (2005), Lentz, Barrett and Hoddinott (2005), Harvey and Lind (2005), Barrett (2006), Awokuse (2006) and Burrows (2011) among many others. The next section discusses the methodology used for this study.

\section{Methodology}

\subsection{Sampling and Data collection}

The study makes use of primary data gathered and computed from sample surveys of 300 households in rural Zimbabwe. The areas of concern were in the Gokwe North and South districts of the Midlands province. The data used in model is dichotomous response data. Subsequently, the Binary Probit technique is utilised to estimate the model.

\subsection{Empirical Model}

The Probit model is presented based on McFadden's approach (Zarembka, 1973) which postulates that individual decisions are influenced by an unobservable utility index $\left({ }^{I_{i}}\right)$ which is influenced by at least one explanatory variable. The larger the utility index, the larger the possibility of a certain decision being taken (Gujarati, 2004). ${ }^{I_{i}}$ is expressed below.

$I_{i}=\alpha+\beta_{n i} X_{n i}$ Supposing the utility index surpasses a threshold index level $\left({ }_{i}^{*}\right)$, a decision is made. The threshold, like the utility index, is unobservable and therefore impossible to estimate. Assuming normality with similar mean and variance, the probability that $I_{i}^{*} \leq I_{i}$ is computed in a standardised cumulative distribution function (CDF) of the form: $P_{i}=P(Y=1 \mid X)=P\left(I_{i}^{*} \leq I_{i}\right)=P\left(Z_{i} \leq \alpha+\beta_{n i} X_{n i}\right)=F\left(\alpha+\beta_{n i} X_{n i}\right)$

Where ${ }^{P(Y=1 \mid X)}$ means that the probability an event occurs subject to explanatory variables and where $Z \sim N\left(0, \sigma^{2}\right)$. F is the standard normal CDF which estimates the probability of the event occurring.

$F\left(I_{i}\right)=\frac{1}{\sqrt{2 \pi}} \int_{-\infty}^{I_{i}} e^{-z^{2} / 2} d z$ 


\subsection{Model Specification}

The theoretical framework is based on an amalgamation of the theory of labour force participation and the theory of labour supply thus the Labour-Leisure choice framework. The model postulates that individuals are primarily faced with the decision whether or not to participate in the labour market. Supposing the individuals decide to enter the workforce, they are then faced with the choice of money hours of work to allocate towards work given their preference for leisure and the daily time constraints. The theory therefore states that labour supply or the number of work hours $(L s)$ that an individual is willing to provide is a function of the labour income $\left(Y_{L}\right)$ or wage that they receive, the non-labour income $\left(Y_{N L}\right)$ (such as accumulated wealth, welfare grants, lottery winnings), given the individual's taste for leisure $I$, all subject to a given time constraint $(T)$. This is shown as:

$$
L_{s}=f\left(Y_{L}, Y_{N L}, l\right) T
$$

To specify the relevant model, the study adopts the empirical model framework in Kooreman and Kapteyn (1985).

$$
w_{m} l_{m}+w_{f} l_{f}+y=u+w_{f} T+w_{m} T
$$

The model assumed a stable utility function that is maximised by each household i.e. $U\left(I_{m}, I_{f}, y\right)$, where $I_{m}, I_{f}$ and $y$ denote male leisure, female leisure and total household consumption respectively. In model $1.1 w_{m}$ and $w_{f}$ show the male and female wage rates respectively, $T$ is the time constraint and $u$ the unearned household income ${ }^{5}$. The model is modified and adopted as:

$$
\begin{aligned}
& P_{i}=\mathrm{E}\left(W E_{i}=1 \mid X_{i}\right)=\alpha+\beta_{1} F A I D_{i}+\beta_{2} W_{I N C_{i}}+\beta_{3} A I N C_{i}+\beta_{4} E D U_{i}+\beta_{5} S H L D_{i} \\
& +\beta_{6} G E N D E R_{i}+\beta_{7} G I N P U T_{i}+\beta_{8} A G E_{i}+\varepsilon_{i}
\end{aligned}
$$

As the $P_{i}$ increases it implies that $W E_{i}$ is also rising. This is subject to the variables:

FAIDi: Food Aid (1 if received successively over 5 years, 0 otherwise)

WINC: Wage Income (1 if yes; 0 otherwise)

AINC: Alternative Income (1 if yes; 0 otherwise)

EDU: Education level (1if completed O'Level, 0 otherwise)

$S H L D_{i:}$ Household Size (1 if more than 5 members older than 12 years; 0 otherwise)

GENDER: Gender (1 if female; 0 otherwise)

GINPUT: Government inputs ( 1 if inputs received continuously over a minimum of 5 years; 0 otherwise)

$A G E_{i:}$ Age of family head (1 if 50 years+; 0 otherwise)

\begin{tabular}{|c|c|c|c|c|c|}
\hline \multicolumn{6}{|c|}{$\begin{array}{l}\text { Dependent Variable: WE } \\
\text { Method: ML - Binary Probit (Quadratic hill climbing) }\end{array}$} \\
\hline Variable & Coefficient & Std. Error & z-Statistic & Prob. & Probability Change \\
\hline WINC & -0.418621 & 0.378364 & -1.106395 & 0.2686 & -0.14103 \\
\hline AINC & -0.331044 & 0.268256 & -1.234060 & 0.2172 & -0.11841 \\
\hline GENDER & -0.724488 & 0.273045 & -2.653368 & 0.0080 & -0.18235 \\
\hline EDU & 0.759483 & 0.167264 & 4.540632 & 0.0000 & 0.36805 \\
\hline AGE & -0.507468 & 0.268487 & -1.890105 & 0.0587 & -0.16031 \\
\hline SHLD & 0.190623 & 0.076067 & 2.505976 & 0.0122 & 0.08466 \\
\hline GINPUT & -0.018702 & 0.288321 & -0.064865 & 0.9483 & -0.00778 \\
\hline FAID & -0.420048 & 0.067406 & -6.231638 & 0.0000 & -0.14135 \\
\hline $\mathrm{C}$ & 1.403596 & 0.631218 & 2.223630 & 0.0262 & \\
\hline McFadden R-squared & 0.205011 & \multicolumn{2}{|c|}{ LR statistic } & \multicolumn{2}{|r|}{82.78497} \\
\hline Obs with Dep $=0$ & 180 & \multicolumn{2}{|c|}{ LR probability } & \multicolumn{2}{|r|}{0.0000} \\
\hline Obs with Dep=1 & 120 & \multicolumn{4}{|c|}{ Total obs 300} \\
\hline
\end{tabular}

\section{Findings}

\subsection{Analysis of outcomes}

Table 1: Binary Probit Findings

Table 1 above shows the estimation output of the probit regression model. The probit coefficient is vital in showing the

${ }_{5}$ This captures the impact of non-wage income such as social security benefits, lottery wins, bequests etc. 
relationship between the dependent factor and the explanatory variables. The study though is more concerned with the changes in the dependent variable (WE) subject to variations in the regressors. The estimation output shows that half of the explanatory variables i.e. GENDER, EDU, SHLD and FAID are statistically significant. These provide the core of importance in the analysis. All the explanatory variables are dichotomous and therefore take the values 0 or 1 . GENDER (significant at 5\%; -2.653 p-value 0.008) implies that the as one considers males rather than females, the probability of preferring to produce for themselves (WE) declines $18.2 \%$ ceteris paribus. This finding can be inferred as that in rural Zimbabwe, female led households are more inclined towards working and self sustenance rather than rely on humanitarian assistance compared to male-opinionated households.

EDU (significant at 5\%; $4.541 \mathrm{p}$-value 0.000 ) shows that individuals with a basic high school completion (Ordinary level) are $36.8 \%$ more likely to prefer to produce and sustain their households on their own. This finding is consistent with basic theory which implies that more educated individuals are likely to be more forward thinking and non-averse towards self-improving and rewarding work. The size of the household SHLD is also a statistically significant variable (significant at 5\%; $2.506 \mathrm{p}$-value 0.012 ). this result implies that households with more than 5 members older than 12 years have work ethic $8.5 \%$ greater than households with less than/or 5 members older than 12 years. The last significant variable FAID (significant at 5\%; -6.232 p-value 0.000) implies a negative relationship between continuously food aid receipt and work ethic. The output shows that for households that received food aid continuously over 5 years, WE is $14.1 \%$ less than households that do not fit that criterion ceteris paribus. This finding is important because it reinforces the theoretical postulation that increments in non-wage and non-labour rewards are likely to reduce labour supply and diminish attitude towards work. WINC and AINC show that households that receive wages from other employment and those that receive alternative income e.g. from working relatives have WE which is $14.1 \%$ and $11.8 \%$ less than those that have no income respectively. These findings are insignificant. Similarly, AGE, shows that households led by individuals older than 50 years are $16 \%$ more likely to prefer humanitarian aid. GINPUT implies that individuals who receive free governmentsupplied inputs are $0.7 \%$ less willing to produce for themselves. These findings, particularly the latter are insignificant and cannot be considered to affect individuals' attitudes towards work in rural Zimbabwe.

\subsection{Diagnostic tests}

Table 2: Hosmer-Lemeshow and Andrews' tests

\begin{tabular}{|c|c|c|c|}
\hline \multicolumn{4}{|c|}{$\begin{array}{l}\text { Goodness-of-Fit Evaluation for Binary Specification } \\
\text { Andrews and Hosmer-Lemeshow Tests }\end{array}$} \\
\hline H-L Statistic & 6.2302 & Prob. Chi-Sq(8) & 0.6215 \\
\hline Andrews Statistic & 10.2005 & Prob. Chi-Sq(10) & 0.4231 \\
\hline
\end{tabular}

The Hosmer-Lemeshow ( $\mathrm{H}-\mathrm{L})$ and Andrews' tests are tests for the overall fit of the model in accounting for the explanatory variable. Both tests have the null hypothesis that the model does not fit. The null hypotheses would not be rejected if the tests were statistically significant at $5 \%$. The $\mathrm{H}-\mathrm{L}$ test statistic is 6.230 with $\mathrm{X}^{2}$ probability value of 0.622 . This means that the test is insignificant resulting in the null hypothesis being rejected. According to the $\mathrm{H}-\mathrm{L}$ test, the goodness-of-fit of the model is high. The Andrews' statistic is 10.201 with a $x^{2}$ probability value of 0.423 which is larger than 0.05 and is thus insignificant. This implies that the null hypothesis cannot be accepted. The two tests therefore concur with each other. Additionally, the $0.000 \mathrm{p}$-value for the LR statistic confirms that the coefficients are suitable in accounting for trends in the regressand. It is concluded that the model is robust and fit for the analysis.

\section{Conclusion}

The findings of this study illustrate a particularly disturbing scenario, or the emergence of one. Regardless of the attitudes of some rural citizens towards self sustenance subject to minor variables (EDU and SHLD), the situation in rural Zimbabwe is disconcerting. It is clear that a degree of dependency has settled and maybe fostering further. Food aid granted by humanitarian organisations has become a norm in rural Zimbabwe, especially the drought-prone areas. Naturally, the inhabitants of these lands have become accustomed to annual or even more frequent receipt of such assistance. The result has been an adverse approach towards providing for themselves through subsistence agriculture that existed before the widespread and consistent humanitarian aid. Furthermore, the Government sponsored agriculture input scheme has debunked the need for sustained production. The norm in rural Zimbabwe was that households would produce in excess of the consumption requirement in order to provide for the succeeding seasons seed. The almost- 
guaranteed free and/or subsidised inputs reduce the need for excess production to cater for succeeding period's inputs.

\section{References}

Awokuse, T.O., (2006) "Assessing the Impact of Food Aid on Recipient Countries: A Survey." Food and Agriculture Organisation 6(11). [Online] Available: http://www.fao.org/es/esa. Accessed [19 July 2013].

Barrett, C.B., (2006) "Food aid's intended and unintended consequences." Cornell University.

Barrett, C.B., and Maxwell, D., (2005) "Food Aid after Fifty years." Routledge: London.

Burrows, T., (2011) "Food aid to developing countries." AlT Language Center.

Habte, E., and Mielke, K., (2005) "What are the effects of external food aid on vulnerable and fragile states? Do methods of delivery matter?" Centre for Development Research. University of Bonn.

Hammond, L., Bush, J., Savage, K., and Harvey, P., (2005) "The effect of food aid on household migration patterns and implications for emergency food assessment." World Food Programme, Emergency Needs Assessment Branch.

Harvey, P., and Lind, J., (2005) "Dependency and Humanitarian relief: A critical analysis." Overseas Development Institute.

Hoddinott, J., (2003) "Examining the incentive effects of food aid on household behaviour in rural Ethiopia." International Food Policy Research Institute.

Kooreman, P., and Kapteyn, A., (1985) "The Systems Approach to Household Labor Supply in the Netherlands." De Enonomist 133 (1).

Lentz, E., Barrett, C.B., and Hoddinott, J., (2005) "Food Aid and Dependency: Implications for emergency food security assessment." World Food Program.

Lipsey, R., and Chrystal, A., (2007) "Economics." Oxford press: New York.

Malinvaud, E., (1966) "Statistical Methods of Econometrics." Rand McNally: Chicago.

Organisation of Economic Cooperation and Development (OECD)., (2013) "Organisation of Economic Cooperation and Development: Zimbabwe." [Online]. Available: 05 January 2014. Accessed: http://www.oecd.org/countries/zimbabwe

Siyoum, A.D., Hilhorst, D., and Van Uffelen, G-J., (2012) "Food Aid and Dependency syndrome in Ethiopia: Local perceptions." Journal of Humanitarian Assistance.

WFP World Food Program., (2012) "WFP fighting hunger worldwide:Zimbabwe." [Online] Available: http://www.wfp.org/countries/ zimbabwe/publications Accessed [03 September 2013].

Zarembka, P., (1973) "Frontiers in Econometrics." Academic Press. New York. 